\title{
Evaluation and Verification of Barley Genotypes with Known Genes for Resistance to Barley yellow mosaic virus and Barley mild mosaic virus Under Field Conditions in South Korea
}

\author{
Hong-Sik Kim ${ }^{1 *}$, Seong-Bum Baek², Dea-Wook Kim², Jong-Jin Hwang ${ }^{2}$ and Si-Ju Kim² \\ ${ }^{1}$ International Technology Cooperation Center, Rural Development Administration, Suwon 441-707, Korea \\ ${ }^{2}$ Upland Crop Division, National Institute of Crop Science, Rural Development Administration, Suwon 441-857, Korea \\ (Received on September 8, 2011; Revised on October 26, 2011; Accepted on October 28, 2011)
}

\begin{abstract}
Soil-borne barley yellow mosaic disease caused by Barley yellow mosaic virus (BaYMV) or Barley mild mosaic virus (BaMMV) gives a serious threat to the winter barley cultivated in the southern regions in Korea. It is important to develop resistant varieties for stable and high-yield production. The objectives of this study were to evaluate 22 genotypes of exotic barley germplasms carrying the resistance genes ryml through rym12, with the exception of rym10, and to determine the genes that confer resistance to BaYMV or BaMMV in Korea. Using the traditional visual scoring of symptoms at 4 locations over 3 years, average disease rate values differed $(P<0.001)$ among the genotypes. ELISA test revealed the presence of both BaYMV and BaMMV in all of the field sites but Jinju and significantly different rates of infection among genotypes and years. Barley genotypes differed in how virus quantities and pathogen-induced symptoms were correlated, especially in response to BaYMV. Disease incidence was affected by the climatic conditions present during the early growing stage before overwintering. A Chinese landrace, 'Mokusekko 3', carrying ryml and rym5 was comparatively resistant at all locations studied. The barley genotypes carrying either rym6 or rym 9 were susceptible to the viral strains. The genotypes carrying rym5 were resistant in Jinju and Milyang but susceptible in Iksan and Naju. The resistance genes rym 2 and rym3 were effective in local strains and would be potent contributors to disease resistance.
\end{abstract}

Keywords : barley, Barley yellow mosaic virus (BaYMV), Barley mild mosaic virus (BaMMV), field resistance

Soil-borne viral diseases have become important in Korea, where about $40 \%$ of barley-growing fields have already been infected with these viruses (So et al., 1990, 1991). Since the disease symptoms of yellow and wilted leaves

\footnotetext{
*Corresponding author.

Phone) +82-31-299-2282, FAX) +82-31-293-9359

E-mail) kimhongs@korea.kr
}

and stems were found in the barley fields of southern Korea in the 1970s, the first pathological occurrence of Barley yellow mosaic virus (BaYMV) was reported in 1981 (Lee, 1981); Barley mild mosaic virus (BaMMV) was first reported in 1993 (So et al., 1997). BaYMV and BaMMV are positive single-strand RNA viruses belonging to the genus Bymovirus in the family Potyviridae. Lee et al. (1998) isolated a BaYMV strain that was distributed in the southern region of Korea and found that this virus consisted of two RNA molecules $7.6 \mathrm{~kb}$ and $3.5 \mathrm{~kb}$ in length. Recent surveys revealed that BaYMV and BaMMV were mainly dominant types of mosaic virus in fields in Korea (Park et al., 2007; So et al., 1997). The reactions of different barley genotypes were different for resistance when infected with these viruses.

In recent years, BaYMV and BaMMV have been problematic for winter barley cultivating regions around the world, including China, England, Germany, Japan and southern European countries. Based on host resistance and pathogen virulence on barley genotypes, three strains (BaYMV-I, -II, and -III) for BaYMV and two (BaMMVKa1 and -Na1) for BaMMV were reported in Japan (Kashiwazaki et al., 1989; Nomura et al., 1996). In Europe, two BaYMV strains (BaYMV and BaYMV-M) and one BaMMV strain were also reported (Huth and Adams, 1990).

Because BaYMV and BaMMV are transmitted by a soil fungal pathogen, Polymyxa graminis Led. (Toyama and Kusaba, 1970), chemical pesticides are not effective in controlling the disease. However, it is possible to control such diseases by developing resistant varieties. In recent years, sixteen resistance genes have been reported for BaYMV and BaMMV in barley germplasm collections. Most of these genes were found based on the interaction of standard genotypes with virus strains from Japan and European countries.

Previous studies reported that the infection and occurrence of BaYMV are known to be influenced by climate and by the soil environment where plants are grown 
(Park et al., 2003; Schenk et al., 1995). The risk of development of soil-borne virus disease varies yearly and depends on the infection level of a given field or region. The disease severity of barley genotypes is complex; it depends on the presence of single- or multi-virus infections, the interactions between plants and the root-infecting vector transmitting BaYMV and BaMMV, and natural escape from viral infection in the field (Kanyuka et al., 2003; Suh, 1995).

In Korea, four different local types of BaYMV and BaMMV were classified according to their genomic similarity in the region of viral RNA 1 of BaYMV (Park et al., 2007). Because the pathogenic responses to barley genotypes are different among local types and even within each local type, it is important to classify BaYMV and/or BaMMV strains by their interactions with host plants, such as the resistance versus susceptibility of barley genotypes. The objectives of this study were to evaluate 22 genotypes of exotic barley germplasms carrying the resistance genes rym1 through rym12, with the exception of rym10, and to determine the genes that confer resistance to BaYMV or BaMMV in Korea.

\section{Materials and Methods}

Plant materials. Twenty-two barley genotypes were evaluated for field resistance to BaYMV and/or BaMMV as the standard differential representatives of the resistance genes rym 1 through rym 12, with the exception of rym 10 . These 22 genotypes and an additional 5 genotypes have various geographical origins, including Australia (1), Bulgaria (1), China (1), Germany (2), Japan (12), Korea (7), Russia (2), and Yugoslavia (1), as presented in Table 1. Three genotypes - Russia 57, Muju Covered 2 and 10247 - were provided by the Barley Germplasm Center, Research Institute for Bioresources at Okayama University, Japan.

Field test. Diagnostic responses of a set of differential varieties to local strains of BaYMV and BaMMV were determined based on the appearance of disease symptoms on the plants in the consistently infested field. The field test was conducted in a completely randomized design with two replications at four locations: (1) the Department of Rice and Winter Cereal Crops, National Institute of Crop Science (NICS), Rural Development Administration (RDA) at Iksan, Jeonbuk Province; (2) the Department of Functional Crops, NICS, RDA at Milyang, Gyeongnam Province; (3) the Gyeongsangnamdo Agricultural Research Extension Service at Jinju, Gyeongnam Province; and (4) the Jeonnam Agricultural Research Extension Service at Naju, Jeonnam Province. These experimental field sites are suitable for conducting field evaluation and verification for barley genotypic reaction against BaYMV and BaMMV because they have a long history of $P$. graminis infection and have been used in the breeding trials for the Korean barley breeding program.

Evaluation of disease incidence was made for a period of 3 years starting in 2003. Approximately 20-25 plants of each barley genotype were planted in the row-plot in rows 2 meters long and $40 \mathrm{~cm}$ apart. Each year, seeds were sown between mid- and late October. A hull-less, six-rowed Korean barley cultivar, Baekdong, and a hulled, two-rowed Korean barley cultivar, Sacheon 6, were also planted as susceptible check varieties in every 10th row of the plot. Field assessments of disease rates were visually determined when mosaic and yellow-colored disease symptoms appeared on the newly developed leaves of 10-15 overwintered plants per genotype in mid- and late March after the winter season. Visual scoring of symptoms assigned observed values from 0 for resistance to 9 for susceptibility. The plants were scored as susceptible when at least one leaf with mosaic disease symptoms was observed. To study the climatic influences on the plant disease and infection rates of BaYMV and BaMMV, meteorological data on temperature (average, lowest and highest) and precipitation in the cities where the experimental field sites are located were analyzed for two periods. The first period was from planting to overwintering (October 1st - December 31st) and the second from the overwintering stage to the re-growth stage (January 1st March 31st). These variable climatic data of the experimental periods and locations were obtained from the website (http://www.kma.go.kr/) of the Korea Meteorological Administration. For the Naju and Iksan experimental sites, the climatic data of Kwangju and Jeonju, which were approximately 20 kilometers away from Naju and Iksan, respectively, were used as alternatives.

ELISA test. To verify the viral infection in the plants with or without disease symptoms, a double antibody sandwich (DAS) Enzyme-Linked ImmunoSorbent Assay (ELISA) with an alkaline phosphatase-conjugated antibody was conducted. An antigen for the specific diagnosis of BaYMV/ BaMMV infections in the ELISA system was prepared as previously described (Clark and Adams, 1977). Single or mixed infections with two different virus types were monitored by using commercially available universal antibodies of BaYMV and BaMMV for the ELISA kit (Agdia Inc., Indiana, USA). In the antibody-coated 96-well microtiter plates, $100 \mu \mathrm{l}$ aliquots of the test samples were loaded into individual wells. Test samples for individual barley genotypes were prepared by grinding $0.3 \mathrm{~g}$ bulked leaf tissue of the plants in the $3 \mathrm{ml}$ extraction buffer. These sampled plants were visually scored as diseased or had uncertain infection symptoms. After incubation of the test samples in 
the plates overnight at $4{ }^{\circ} \mathrm{C}$, the plates were washed with PBS-Tween wash buffer (1x) five to six times. The enzyme reactions were completed by incubation of plates at $37^{\circ} \mathrm{C}$ for 4 hours after loading $100 \mu \mathrm{l}$ aliquots of anti-virus conjugate diluted to a ratio 1:100 in conjugate buffer. After washing the plates with PBS-Tween wash buffer (1x) five to six times, $100 \mu \mathrm{l}$ aliquots of the freshly prepared substrate solution $(1 \mathrm{mg} / \mathrm{ml}$ of p-nitrophenyl phosphate in the PNP substrate buffer) were added to each test well of plates. Upon incubation at room temperature for 60 minutes, the entire plate was placed into a plate reader, and the amount of colored product was determined at A405 nm.

Statistical analysis. Analysis of variance was conducted on the field data for disease rating and ELISA values for the 27 genotypes with PROC GLM in SAS (SAS Institute, North Carolina, USA). The data for all genotypes in each year and location of testing were analyzed separately or combined for different environments (years and locations). Pearson product-movement correlations were calculated by PROC CORR in SAS to compare disease ratings of genotypes in different environments with ELISA values and to compare the level of disease incidence and the climatic factors. The correlation values were calculated from the means of genotypes in each environment and across environments.

\section{Results and Discussion}

Responses to BaYMV and BaMMV at different sites and in different years. Barley genotypes were evaluated

Table 1. Average rates of disease severity in field tests and average ELISA values to BaYMV/BaMMV for the 27 barley genotypes in each and across the study years

\begin{tabular}{|c|c|c|c|c|c|c|c|c|c|c|c|c|}
\hline \multirow{2}{*}{ Genotype } & \multirow{2}{*}{ Origin } & \multirow{2}{*}{ Gene } & \multicolumn{4}{|c|}{ Disease rates $(0-9)$} & \multicolumn{3}{|c|}{ ELISA (BaYMV) } & \multicolumn{3}{|c|}{ ELISA (BaMMV) } \\
\hline & & & 2003 & 2004 & 2005 & Mean $^{\mathrm{a}}$ & 2004 & 2005 & Mean $^{b}$ & 2004 & 2005 & Mean $^{c}$ \\
\hline Mokusekko 3 & China & rym1, rym5 & 0.0 & 0.0 & 0.1 & 0.0 & 0.196 & 0.151 & 0.174 & 0.161 & 0.137 & 0.149 \\
\hline MK 231-60 & Japan & rym1 & 2.8 & 1.5 & 1.9 & 2.0 & 0.235 & 0.194 & 0.215 & 0.150 & 0.137 & 0.144 \\
\hline Mihori Hadaka 3 & Japan & rym2 & 1.5 & 2.0 & 0.5 & 1.3 & 0.151 & 0.146 & 0.149 & 0.156 & 0.135 & 0.145 \\
\hline Ishuku Shirazu & Japan & rym3 & 1.1 & 0.5 & 1.1 & 0.9 & 0.157 & 0.188 & 0.172 & 0.152 & 0.215 & 0.184 \\
\hline Ea 52 & Japan & rym3 & 0.3 & 1.5 & 1.9 & 1.2 & 0.158 & 0.192 & 0.175 & 0.336 & 0.333 & 0.335 \\
\hline Haganemugi & Japan & rym3 & 1.5 & 3.0 & 1.9 & 2.1 & 0.170 & 0.247 & 0.208 & 0.491 & 0.504 & 0.498 \\
\hline Franka & Germany & rym4 & 2.3 & 1.5 & 1.5 & 1.8 & 0.199 & 0.205 & 0.202 & 0.154 & 0.137 & 0.145 \\
\hline $17-22$ & Japan & rym4 & 3.1 & 3.9 & 1.9 & 3.0 & 0.210 & 0.143 & 0.177 & 0.136 & 0.136 & 0.136 \\
\hline Sonate & Germany & rym $4 m$ & - & - & 3.9 & 3.9 & - & 0.201 & 0.201 & - & 0.135 & 0.135 \\
\hline Tokushima Mochi Hadaka & Japan & rym4y & 2.1 & 3.0 & 1.5 & 2.2 & 0.151 & 0.147 & 0.149 & 0.492 & 0.359 & 0.425 \\
\hline Misato Golden & Japan & rym5 & 3.3 & 2.6 & 3.0 & 3.0 & 0.162 & 0.194 & 0.178 & 0.200 & 0.286 & 0.243 \\
\hline Kinuyutaka & Japan & rym5 & 3.3 & 2.9 & 3.0 & 3.0 & 0.142 & 0.163 & 0.152 & 0.346 & 0.330 & 0.338 \\
\hline Sinhobori & Korea & rym5 & 2.8 & 2.5 & 2.8 & 2.7 & 0.161 & 0.153 & 0.157 & 0.192 & 0.306 & 0.249 \\
\hline Woogye I-41 & Japan & rym5a & - & - & 0.3 & 0.3 & - & 0.144 & 0.144 & - & 0.134 & 0.134 \\
\hline Amagi Nijo & Japan & rym6 & 6.5 & 5.6 & 5.4 & 5.8 & 0.255 & 0.272 & 0.263 & 0.247 & 0.158 & 0.203 \\
\hline Prior & Australia & rym6 & - & 4.6 & 4.4 & 4.5 & 0.237 & 0.221 & 0.229 & 0.132 & 0.136 & 0.134 \\
\hline HHor 3365 & Russia & rym7 & - & - & 0.5 & 0.5 & - & 0.149 & 0.149 & - & 0.136 & 0.136 \\
\hline 10247 & Yugoslavia & rym8 & - & - & 3.1 & 3.1 & - & 0.171 & 0.171 & - & 0.285 & 0.285 \\
\hline Bulgarian 347 & Bulgaria & rym9 & 4.4 & 4.3 & 5.0 & 4.5 & 0.225 & 0.190 & 0.207 & 0.141 & 0.137 & 0.139 \\
\hline Russia 57 & Russia & rym 11 & - & - & 3.5 & 3.5 & - & 0.140 & 0.140 & - & 0.260 & 0.260 \\
\hline Muju Covered 2 & Korea & rym 12 & - & - & 3.6 & 3.6 & - & 0.150 & 0.150 & - & 0.132 & 0.132 \\
\hline Jochiwon Covered 2 & Korea & rym 12 & - & - & 3.8 & 3.8 & - & 0.143 & 0.143 & - & 0.392 & 0.392 \\
\hline Chalbori & Korea & & 0.1 & 0.5 & 1.0 & 0.5 & 0.196 & 0.220 & 0.208 & 0.142 & 0.248 & 0.195 \\
\hline Namhaebori & Korea & & 2.4 & 3.1 & 3.0 & 2.8 & 0.167 & 0.161 & 0.164 & 0.476 & 0.270 & 0.373 \\
\hline Ko A & Japan & & 7.9 & 7.3 & 7.1 & 7.4 & 0.201 & 0.154 & 0.178 & 0.132 & 0.135 & 0.134 \\
\hline Sacheon 6 & Korea & susceptible & 7.4 & 7.3 & 7.1 & 7.3 & 0.268 & 0.242 & 0.255 & 0.135 & 0.135 & 0.135 \\
\hline Baekdong & Korea & susceptible & 7.8 & 7.6 & 7.6 & 7.7 & 0.252 & 0.242 & 0.247 & 0.273 & 0.295 & 0.284 \\
\hline Mean & & & 3.2 & 3.3 & 3.0 & 3.1 & 0.195 & 0.182 & 0.184 & 0.232 & 0.222 & 0.225 \\
\hline $\operatorname{LSD}(P<0.001)$ & & & 0.9 & 0.9 & 0.9 & 0.9 & 0.074 & 0.061 & 0.054 & 0.125 & 0.047 & 0.065 \\
\hline
\end{tabular}

${ }^{a}$ Mean, Average of disease rates evaluated in 3 years over 4 locations.

b,c Mean, Average of ELISA values to BaYMV/BaMMV measured in 2 years over 4 locations, respectively. 
for disease rates by traditional visual scoring of symptom expression at the four locations from 2003 to 2005. The incidence of BaYMV and BaMMV symptoms in the fields over the years and locations is shown in Tables 1 and 2, respectively. The significance of the effects of genotype, location, year and the interactions of location and year with genotypes on field disease rates and ELISA values of BaYMV and BaMMV are presented in Table 3. Genotype differences were highly significant for all variables of disease incidence. The average disease rate of the 27 genotypes over all of the environments ranged from 0.0 to 7.7 (Table 1). The susceptible indicator genotypes to BaYMV and BaMMV, Baekdong and Sacheon 6, had consistently high disease ratings $(>7)$ over the three-year period regardless of field locations. Some genotypes, such as Prior, Bulgarian 347, Amagi Nijo and Ko A, were also highly susceptible, with a disease rating range of 4.5-7.4. Chalbori, Ishuku Shirazu and Mokusekko 3, however, showed high levels of field resistance, with visual ratings $<1$.

Location and year had highly significant effects on the field disease rates. In particular, results of the study showed significant variation over locations $(P<0.001)$ (Table 3$)$ : the average disease rate of barley genotypes was the highest in Iksan (4.0), followed by Naju (3.6) and Milyang (2.9), as shown in Table 2 . The variation of disease incidence among locations may have been the result of differences in the disease responses of genotypes, the distribution of disease and pathogenicity of local virus strains. For example, the average disease rate in Jinju (1.9) was lower than the other sites, as only BaYMV was detected using ELISA. Barley genotypes with no disease symptoms in Jinju, such as 10247, Franka, Haganemugi, Jochiwon Covered 2 and

Table 2. Average rates of disease severity in field tests and ELISA values to BaYMV/BaMMV for the 27 barley genotypes grown in the four study locations from 2003 to 2005

\begin{tabular}{|c|c|c|c|c|c|c|c|c|c|c|c|c|}
\hline \multirow{2}{*}{ Genotype } & \multicolumn{4}{|c|}{ Disease rate $(0-9)$} & \multicolumn{4}{|c|}{ ELISA (BaYMV) } & \multicolumn{4}{|c|}{ ELISA (BaMMV) } \\
\hline & Jinju & Milyang & Naju & Iksan & Jinju & Milyang & Naju & Iksan & Jinju & Milyang & Naju & Iksan \\
\hline Mokusekko 3 & 0.0 & 0.2 & 0.0 & 0.0 & 0.161 & 0.156 & 0.216 & 0.162 & 0.135 & 0.130 & 0.173 & 0.159 \\
\hline MK 231-60 & 0.7 & 2.8 & 1.0 & 3.7 & 0.277 & 0.182 & 0.136 & 0.264 & 0.158 & 0.133 & 0.132 & 0.152 \\
\hline Mihori Hadaka 3 & 0.7 & 0.5 & 3.0 & 1.2 & 0.157 & 0.141 & 0.136 & 0.161 & 0.137 & 0.130 & 0.169 & 0.146 \\
\hline Ishuku Shirazu & 0.2 & 1.3 & 0.8 & 1.3 & 0.142 & 0.148 & 0.134 & 0.265 & 0.137 & 0.135 & 0.136 & 0.327 \\
\hline Ea 52 & 0.0 & 0.2 & 2.5 & 2.2 & 0.169 & 0.134 & 0.145 & 0.253 & 0.139 & 0.133 & 0.329 & 0.738 \\
\hline Haganemugi & 0.0 & 1.0 & 3.5 & 4.0 & 0.167 & 0.143 & 0.143 & 0.381 & 0.136 & 0.771 & 0.481 & 0.602 \\
\hline Franka & 0.0 & 3.3 & 1.0 & 2.7 & 0.171 & 0.210 & 0.140 & 0.287 & 0.139 & 0.131 & 0.138 & 0.174 \\
\hline $17-22$ & 3.5 & 4.0 & 0.5 & 3.8 & 0.166 & 0.141 & 0.181 & 0.219 & 0.132 & 0.130 & 0.135 & 0.149 \\
\hline Sonate & 0.5 & 4.0 & 5.0 & 6.0 & 0.195 & 0.171 & 0.140 & 0.298 & 0.138 & 0.135 & 0.128 & 0.140 \\
\hline Tokushima Mochi Hadaka & 0.0 & 3.8 & 0.7 & 4.3 & 0.150 & 0.142 & 0.145 & 0.159 & 0.131 & 0.402 & 0.662 & 0.507 \\
\hline Misato Golden & 0.0 & 0.3 & 6.2 & 5.3 & 0.135 & 0.172 & 0.137 & 0.268 & 0.132 & 0.130 & 0.170 & 0.540 \\
\hline Kinuyutaka & 0.0 & 0.8 & 5.7 & 5.7 & 0.143 & 0.135 & 0.144 & & 0.130 & 0.124 & 0.690 & 0.407 \\
\hline Sinhobori & 0.0 & 0.0 & 5.7 & 5.0 & 0.140 & 0.138 & 0.135 & 0.216 & 0.131 & 0.126 & 0.165 & 0.576 \\
\hline Woogye I-41 & 0.0 & 1.0 & 0.0 & 0.0 & 0.140 & 0.159 & 0.144 & 0.135 & 0.132 & 0.139 & 0.128 & 0.139 \\
\hline Amagi Nijo & 6.0 & 5.3 & 6.3 & 5.7 & 0.349 & 0.181 & 0.161 & 0.363 & 0.135 & 0.128 & 0.364 & 0.185 \\
\hline Prior & 5.0 & 4.3 & 4.3 & 4.5 & 0.258 & 0.194 & 0.155 & 0.309 & 0.131 & 0.131 & 0.135 & 0.139 \\
\hline HHor 3365 & 2.0 & 0.0 & 0.0 & 0.0 & 0.180 & 0.151 & 0.131 & 0.135 & 0.142 & 0.135 & 0.127 & 0.139 \\
\hline 10247 & 0.0 & 3.5 & 4.5 & 4.5 & 0.209 & 0.203 & 0.129 & 0.144 & 0.144 & 0.133 & 0.481 & 0.383 \\
\hline Bulgarian 347 & 4.8 & 4.7 & 4.0 & 4.7 & 0.199 & 0.187 & 0.223 & 0.221 & 0.136 & 0.133 & 0.141 & 0.147 \\
\hline Russia 57 & 0.0 & 4.0 & 5.5 & 4.5 & 0.122 & 0.169 & 0.132 & 0.137 & 0.134 & 0.135 & 0.643 & 0.131 \\
\hline Muju Covered 2 & 0.0 & 5.5 & 4.5 & 4.5 & 0.126 & 0.158 & 0.141 & 0.177 & 0.136 & 0.131 & 0.129 & 0.135 \\
\hline Jochiwon Covered 2 & 0.0 & 5.5 & 5.5 & 4.0 & 0.134 & 0.153 & 0.137 & 0.148 & 0.137 & 0.341 & 0.567 & 0.525 \\
\hline Chalbori & 0.0 & 0.0 & 0.0 & 2.2 & 0.124 & 0.132 & 0.154 & 0.422 & 0.127 & 0.129 & 0.179 & 0.346 \\
\hline Namhaebori & 0.3 & 2.2 & 4.8 & 4.0 & 0.161 & 0.129 & 0.182 & 0.184 & 0.211 & 0.399 & 0.463 & 0.419 \\
\hline Ko A & 7.2 & 7.5 & 7.8 & 7.2 & 0.136 & 0.175 & 0.188 & 0.211 & 0.132 & 0.131 & 0.133 & 0.139 \\
\hline Sacheon 6 & 7.3 & 7.0 & 7.7 & 7.0 & 0.496 & 0.171 & 0.150 & 0.203 & 0.136 & 0.129 & 0.133 & 0.141 \\
\hline Baekdong & 7.7 & 7.5 & 7.7 & 7.8 & 0.276 & 0.295 & 0.230 & 0.189 & 0.133 & 0.203 & 0.434 & 0.366 \\
\hline Mean & 1.9 & 2.9 & 3.6 & 4.0 & 0.193 & 0.165 & 0.158 & 0.234 & 0.139 & 0.188 & 0.275 & 0.304 \\
\hline $\operatorname{LSD}(P<0.001)$ & 0.7 & 0.9 & 1.0 & 1.0 & 0.003 & 0.017 & 0.067 & 0.060 & 0.003 & 0.042 & 0.047 & 0.066 \\
\hline
\end{tabular}


Table 3. Analysis of variance for the ratings of disease severity in field tests and ELISA values to BaYMV/BaMMV of the 27 barley genotypes

\begin{tabular}{|c|c|c|c|c|c|c|c|c|c|}
\hline \multirow{2}{*}{ Source } & \multicolumn{3}{|c|}{ Disease rate } & \multicolumn{3}{|c|}{ BaYMV } & \multicolumn{3}{|c|}{ BaMMV } \\
\hline & $\mathrm{DF}^{\mathrm{a}}$ & $\mathrm{MS}^{\mathrm{b}}$ & $F$ value $^{\mathrm{c}}$ & DF & MS & $F$ value & $\mathrm{DF}$ & MS & $F$ value \\
\hline Replication & 1 & 2.3 & $8.2 * *$ & 1 & 0.003 & 1.6 & 1 & 0.018 & $6.8^{*}$ \\
\hline Location (Loc) & 3 & 96.8 & $343.0^{* * *}$ & 3 & 0.100 & $64.8^{* * *}$ & 3 & 0.489 & $179.9 * * *$ \\
\hline Year & 2 & 1.5 & $5.3 * *$ & 1 & 0.001 & 0.6 & 1 & 0.003 & 1.0 \\
\hline Loc $\times$ Year & 6 & 2.3 & $8.3^{* * *}$ & 3 & 0.026 & $16.4^{* * *}$ & 3 & 0.084 & $31.0 * * *$ \\
\hline Genotype & 26 & 97.1 & $344.1 * * *$ & 26 & 0.017 & $11.2 * * *$ & 26 & 0.164 & $60.2^{* * *}$ \\
\hline Genotype $\times$ Loc & 78 & 10.5 & $37.1 * * *$ & 78 & 0.012 & $7.8 * * *$ & 78 & 0.057 & $20.8^{* * *}$ \\
\hline Genotype $\times$ Year & 37 & 2.3 & $8.1 * * *$ & 19 & 0.005 & $3.1 * * *$ & 19 & 0.022 & $8.2 * * *$ \\
\hline Genotype $\times$ Loc $\times$ Year & 111 & 1.5 & $5.3 * * *$ & 57 & 0.013 & $8.4 * * *$ & 57 & 0.017 & $6.4 * * *$ \\
\hline Error & 263 & 0.3 & & 187 & 0.002 & & 187 & 0.003 & \\
\hline
\end{tabular}

${ }^{\mathrm{a}} \mathrm{DF}$, Degrees of Freedom, ${ }^{\mathrm{b}} \mathrm{MS}$, Mean Square

c*, ** and *** indicate significance at $P<0.05, P<0.01$ and $P<0.001$, respectively.

Muju Covered 2, were highly susceptible when grown in the infested fields of the other three sites.

As revealed by ELISA test, whose absorbance values were measured in 2004 and 2005, barley genotypes were differentially infected with BaYMV and BaMMV depending on their resistance levels and locations (Tables 1 and 2). Some resistant and moderately resistant barley genotypes, such as Mokusekko 3, Ishuku Shirazu, Ea 52 and Mihori Hadaka 3, had relatively low ELISA values.

Genotype $\mathrm{x}$ location $\mathrm{x}$ year interactions for all variables were significant (Table 3), suggesting that genotypic differences for disease incidence did not persist across both years and locations. This conclusion is supported by our finding of non-significant correlations of the field disease rating tests for barley genotypes between environments (locations and years), in particular between Naju in 2003-2005 and Milyang in 2003-2004 environments (Table 4).

The correlation between the field disease ratings and
ELISA values of the barley genotypes over locations and years is presented in Table 5. Barley genotypes differed in the manner in which virus quantities and pathogen-induced symptom severity were correlated. Average disease rates across all locations in 2004 and 2005 were significantly correlated with ELISA values of $\operatorname{BaYMV}\left(r=0.6^{* *}\right.$ and $0.42 *$, respectively), but not with ELISA values of BaMMV. In addition, average disease rates in Jinju and Milyang were significantly correlated with ELISA values of BaYMV ( $r=0.67^{* *}$ and $0.58^{* *}$, respectively). In our study, a strong correlation between disease incidence and the amount of virus in the plants was found to exist, with an increase in the susceptible response of plants under high disease pressure induced by quantitative increases of virus density, especially BaYMV. However, no correlation was observed for the locations of Iksan and Naju, where plants were highly infected with BaMMV. In this case, the level of visual symptoms of plants was not correlated with the

Table 4. Correlations of the field disease rating tests for barley genotypes between twelve environments (locations and years)

\begin{tabular}{|c|c|c|c|c|c|c|c|c|c|c|c|}
\hline & $\begin{array}{l}\text { Jinju } \\
2003\end{array}$ & $\begin{array}{l}\text { Jinju } \\
2004\end{array}$ & $\begin{array}{l}\text { Jinju } \\
2005\end{array}$ & $\begin{array}{c}\text { Milyang } \\
2003\end{array}$ & $\begin{array}{c}\text { Milyang } \\
2004\end{array}$ & $\begin{array}{c}\text { Milyang } \\
2005\end{array}$ & $\begin{array}{l}\text { Naju } \\
2003\end{array}$ & $\begin{array}{l}\text { Naju } \\
2004\end{array}$ & $\begin{array}{l}\text { Naju } \\
2005\end{array}$ & $\begin{array}{l}\text { Iksan } \\
2003\end{array}$ & $\begin{array}{l}\text { Iksan } \\
2004\end{array}$ \\
\hline Jinju 2004 & $0.98 * * * a$ & & & & & & & & & & \\
\hline Jinju 2005 & $0.97 * * *$ & $0.96 * * *$ & & & & & & & & & \\
\hline Milyang 2003 & $0.88 * * *$ & $0.87 * * *$ & $0.85 * * *$ & & & & & & & & \\
\hline Milyang 2004 & $0.82 * * *$ & $0.81 * * *$ & $0.80 * * *$ & $0.95 * * *$ & & & & & & & \\
\hline Milyang 2005 & $0.94 * * *$ & $0.92 * * *$ & $0.75 * * *$ & $0.91 * * *$ & $0.86^{* * *}$ & & & & & & \\
\hline Naju 2003 & $0.57^{*}$ & $0.58 * *$ & $0.64 * *$ & 0.42 & 0.43 & $0.62 * *$ & & & & & \\
\hline Naju 2004 & $0.56^{*}$ & $0.62 * *$ & $0.64 * *$ & 0.39 & 0.38 & $0.59^{*}$ & $0.81 * * *$ & & & & \\
\hline Naju 2005 & $0.56^{*}$ & $0.57 * *$ & $0.51 * *$ & 0.39 & 0.39 & $0.61 * *$ & $0.80 * * *$ & $0.93 * * *$ & & & \\
\hline Iksan 2003 & $0.65^{* *}$ & $0.64 * *$ & $0.68 * *$ & $0.63 * *$ & $0.58 * *$ & $0.69^{* *}$ & $0.82 * * *$ & $0.79 * * *$ & $0.85 * * *$ & & \\
\hline Iksan 2004 & $0.66^{* *}$ & $0.65^{* *}$ & $0.67 * *$ & $0.66^{* *}$ & $0.63 * *$ & $0.69 * *$ & $0.65^{* *}$ & $0.73 * *$ & $0.69 * *$ & $0.86^{* * *}$ & \\
\hline Iksan 2005 & $0.66^{* *}$ & $0.59 * *$ & $0.51^{* *}$ & $0.59 * *$ & $0.63 * *$ & $0.66^{* *}$ & $0.73 * *$ & $0.66^{* *}$ & $0.78 * * *$ & $0.81 * * *$ & $0.75^{* * *}$ \\
\hline
\end{tabular}

a*, ** and $* * *$ indicate significance at $P<0.05, P<0.01$ and $P<0.001$, respectively. 
Table 5. Correlations between field disease ratings and ELISA values of the barley genotypes for individual locations and years

\begin{tabular}{|c|c|c|c|c|c|c|}
\hline & \multicolumn{6}{|c|}{ Disease rate } \\
\hline & \multicolumn{4}{|c|}{ Location } & \multicolumn{2}{|c|}{ Year } \\
\hline & Jinju & Milyang & Naju & Iksan & 2004 & 2005 \\
\hline ELISA (BaYMV) & $0.67 * * \mathrm{a}$ & $0.58 * *$ & 0.14 & 0.13 & $0.60 * *$ & $0.42^{*}$ \\
\hline ELISA (BaMMV) & -0.14 & -0.04 & 0.26 & 0.08 & -0.02 & -0.05 \\
\hline
\end{tabular}

a* and $* *$ indicate significance at $P<0.05$ and 0.01 .

density of pathogens. For BaMMV, phenomena of minimal or near-invisible symptoms were often observed for barley genotypes such as Haganemugi, Tokushima Mochi Hadaka, and Ea 52 with high ELISA values. This indicates that there is no correlation between the virus concentration and symptom severity in some cases.

Most of the field sites were infested with both BaYMV and BaMMV, except for Jinju as revealed by ELISA (Table 2 ). Even when both viruses were detected in the plant samples, different infection frequencies were observed among locations on the basis of the number of virusinfected genotypes. Infection with BaMMV was more frequent in Naju, but infection with BaYMV was more frequent in Milyang. Mixed infection with BaYMV and BaMMV was most frequently observed in Iksan. As shown in Table 1, average ELISA values in 2005 were 0.182 for BaYMV and 0.222 for BaMMV and were lower compared to 2004 (0.195 and 0.232, respectively); The effect of year on ELISA values of BaYMV/BaMMV, however, was not significant (Table 3). Less viral infection in 2005, as shown by ELISA, was congruent with low disease rates measured in the same year as compared to 2004. Local variation and interaction with genotypes for ELISA values of BaYMV and BaMMV were statistically significant $(P<0.001)$ (Table 3). For BaYMV, plants showed the highest viral infection in Iksan, with an ELISA value of 0.234 , and the lowest in Naju, with an ELISA value of 0.158. For BaMMV, plants in Iksan also showed the highest infection rate, with an ELISA value of 0.304, and those in Naju were relatively highly infected, with a value of 0.275 (Table 2).
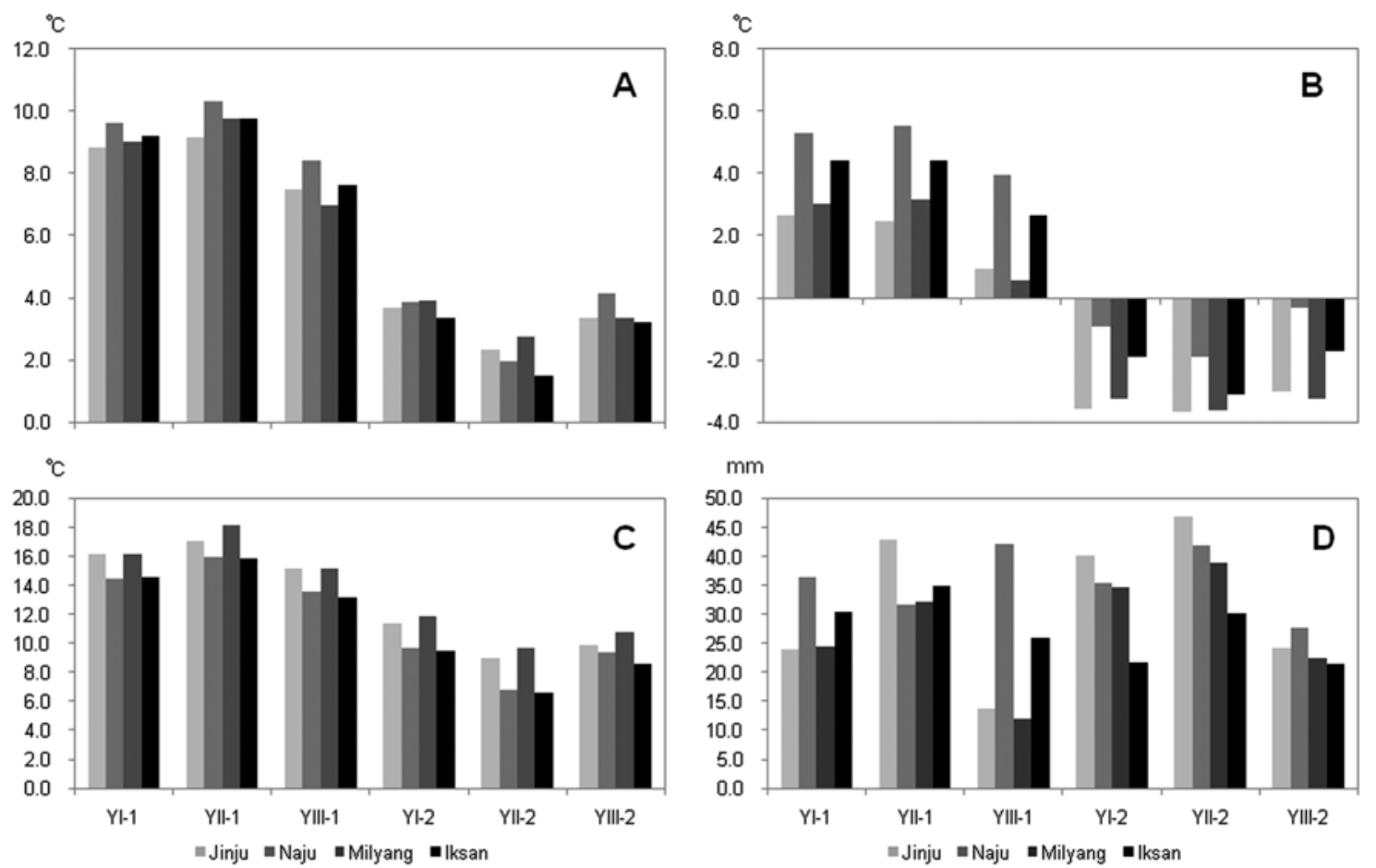

Fig. 1. Mean values of climatic factors of average temperature (A), lowest temperature (B), highest temperature (C) and precipitation (D) in four locations - Jinju, Naju, Milyang and Iksan - before and after the winter season, 2003 to 2006 (YI-1: Oct. 1st - Dec. 31st, 2003; YII-1: Oct. 1st - Dec. 31st, 2004; YIII-1: Oct. 1st - Dec. 31st, 2005; YI-2: Jan. 1st - Mar. 31st, 2004; YII-2: Jan. 1st - Mar. 31st, 2005; YIII-2: Jan. 1st - Mar. 31st, 2006). 
Viral infection and disease incidence of BaYMV and BaMMV have been known to be affected by climatic conditions, particularly before and after the winter season. Other than local differences attributable to geographical environments, temperature variation (among average, highest and lowest temperatures) was lower in 2005 by $1-$ $2{ }^{\circ} \mathrm{C}$ on average than in 2003 and 2004 (Fig. 1). The temperature conditions from October through December were the likely cause of variation in disease incidence among the studied environments. The low disease rate in 2005, especially in Jinju, might have been the result of inhibition of activity of the fungal pathogenic vector $(P$. graminis) in plant viral infection as a result of the low temperature. In 2003 and 2004, the average temperatures (9.2 and $9.8^{\circ} \mathrm{C}$, respectively) in the period of planting through overwintering, i.e., from October to December, were close to $10^{\circ} \mathrm{C}$ for optimum activity of $P$. graminis. In a previous study, Park et al. (2003) reported that the average temperature $\left(10-15^{\circ} \mathrm{C}\right)$ in the early growing stage before wintering was critical for the disease incidence of BaYMV and BaMMV.

As presented in Table 6, our correlation studies between climatic factors and measures of disease incidence revealed that the average lowest temperature was significantly correlated with the disease rate in the field and ELISA values for BaMMV $(P<0.05)$. However, in the overwintering and plant re-growth stage, climatic factors did not significantly affect the incidence of viral disease (Table 6). Our results suggest that the average lowest temperature has a critical impact on the increase of pathogen-induced symptoms and infection of BaMMV.

Identification of major resistance genes to BaYMV and BaMMV. The response to BaYMV/BaMMV among barley genotypes with different resistance genes was analyzed. The three genotypes of Amagi Nijo, Prior, and Bulgarian 347 were susceptible at all study locations. This indicates that the two genes rym6 and rym 9 do not work for field resistance to stains of BaYMV and BaMMV in Korea. Sinhobori, a two-rowed and hulled Korean malting barley carrying rym5, was resistant in Jinju and Milyang but severely susceptible in Naju and Iksan. Similar trends of field resistance were observed in the Misato Golden and Kinuyutaka varieties carrying rym5. Considering that the fields in Naju and Iksan were infested with both BaYMV and BaMMV, those varieties with rym5 were unable to resist strains with different pathogenicities from those in Jinju and Milyang.

Mokusekko 3, a Chinese 6-rowed barley landrace carrying two resistance genes, ryml and rym5, was comparatively resistant to local strains over 3 years. In spite of viral infection as revealed by ELISA, there was no apparent disease symptom of BaYMV and BaMMV in Mokusekko 3. Two more genotypes, Woogye I-41 (rym5a) and HOR3365 (rym7), were also resistant to all local strains when evaluated for one year, but additional field tests will be required to verify their resistance. The genotypes MK 23160 and Misato Golden were not resistant over all field trials even if they had rym 1 and rym5, respectively. This means that the field resistance of Mokusekko 3 may have resulted from the interaction between two genes, as suggested by Okada et al. (2004), and/or the effect of unknown resistance gene(s) to strains of BaYMV and BaMMV in Korea. According to Okada et al. (2004), pyramiding of two genes derived from Mokusekko 3, rather than a single gene alone, was evidently effective for complete resistance to BaYMV strains in Japan.

Barley genotypes carrying rym 2 or rym 3 were resistant in Jinju and Milyang but susceptible in Iksan and unstably resistant in Naju. It was notable, in particular, that Ishuku Shirazu, a Japanese 2-rowed and malting barley variety carrying rym3, was resistant in Naju, but the two genotypes Ea 52 and Haganemugi carrying the same rym3 gene were not. The genotypes carrying rym3 are known to be resistant to all strains of BaYMV, but they are not effective against BaMMV in Japan (Kawada, 1991). Different reactions of rym3-carrying barley genotypes to pathogenic strains between Korea and Japan suggest that there may be one or more resistance genes in Ishuku Shirazu in addition to rym3.

Table 6. Correlations between climatic factors and measures of disease incidence

\begin{tabular}{|c|c|c|c|c|c|c|c|c|}
\hline & \multicolumn{4}{|c|}{ October $1^{\text {st }}-$ December $31^{\text {st }}$} & \multicolumn{4}{|c|}{ January $1^{\text {st }}-$ March $31^{\text {st }}$} \\
\hline & $\begin{array}{l}\text { Avg. } \\
\text { Temp. }\end{array}$ & $\begin{array}{l}\text { High } \\
\text { Temp. }\end{array}$ & $\begin{array}{l}\text { Low } \\
\text { Temp. }\end{array}$ & $\begin{array}{l}\text { Precipi } \\
\text {-tation }\end{array}$ & $\begin{array}{l}\text { Avg. } \\
\text { Temp. }\end{array}$ & $\begin{array}{l}\text { High } \\
\text { Temp. }\end{array}$ & $\begin{array}{l}\text { Low } \\
\text { Temp. }\end{array}$ & $\begin{array}{l}\text { Precipi } \\
\text {-tation }\end{array}$ \\
\hline Disease rate & 0.37 & -0.42 & $0.71^{* \mathrm{~b}}$ & 0.44 & -0.20 & -0.55 & 0.58 & -0.24 \\
\hline ELISA (BaYMV) & 0.05 & -0.12 & 0.08 & -0.14 & -0.62 & -0.58 & -0.26 & -0.20 \\
\hline ELISA (BaMMV) & 0.33 & -0.41 & $0.72 *$ & 0.28 & -0.18 & -0.67 & 0.61 & -0.14 \\
\hline
\end{tabular}

${ }^{a}$ Climatic factors include average temperature, highest temperature, lowest temperature and precipitation. Measures of disease incidence include average field disease ratings and ELISA values of the barley genotypes.

b $*$ indicates significance at $P<0.05$. 
Interestingly, Haganemugi, a Japanese six-rowed hulled barley variety, had been a very important breeding parent for Korean barley improvement via the introduction of its lodging tolerance trait. It is likely that rym3 or unknown resistance gene(s) to BaYMV and BaMMV was naturally and simultaneously selected among the progeny lines developed under the genetic background of Haganemugi at the time when the lodging-tolerance trait was selected for in the early generations of breeding program. Six-rowed hulled Korean barley varieties with the genetic background of Haganemugi, such as Kangbori, Chalbori and Namhaebori, showed good performance for lodging tolerance and BaYMV/BaMMV resistance.

The necessity of disease resistance in different host backgrounds. Barley genotypes with the same resistance genes, such as rym3 or rym4, revealed different levels of disease incidence when evaluated even in the same field. This is because the standard set of resistance genes was established on the basis of their interactions with the isolates of BaYMV and BaMMV in Japan and Europe. For example, a Korean strain of BaMMV was reported to be different from the Japanese and German strains (Lee et al., 1996). Various reactions of barley genotypes for field resistance indicate that Korean strains of BaYMV and BaMMV are more complex and locally differentiated, with different virulence levels compared to those strains in Japan and other European countries.

Some of the BaYMV or BaMMV-resistant genotypes have been reclassified as susceptible in response to the appearance of new strains. In recent years, new variants of BaYMV- and BaMMV-infecting barley genotypes carrying the existing resistance genes have been reported (Hariri et al., 2000, 2003; Konishi et al., 2002). Therefore, it is important to conduct extensive surveys of new sources of resistance genes by evaluating the disease resistance in different host backgrounds at various locations and countries. Integrated gene pyramiding strategies for durable disease-resistance breeding in barley are necessary to promote stable production in the areas where virulence of BaYMV and BaMMV is significant. Many disease-resistance genes have been mapped over the barley genomes by using DNA markers. This biotech-based molecular marker system allows us to conduct selective gene pyramiding of resistance. This system is also important because it is needed to establish a standard set of differential varieties to distinguish Korean pathotypes of BaYMV and BaMMV and to identify resistance genes to different pathogenic strains in Korean environments.

\section{Acknowledgements}

This work was supported in part by a Coordinated Research Project (Contract No. 12823) from the International Atomic
Energy Agency (IAEA), Austria.

\section{References}

Clark, M. F. and Adams, A. N. 1977. Characteristics of the microplate method of enzyme-linked immunosorbent assay for the detection of plant viruses. J. Gen. Virol. 34:475-483.

Hariri, D., Meyer, M. and Prud'homme, H. 2003. Characterization of a new barley mild mosaic virus pathotype in France. Eur. J. Plant Pathol. 109:921-928.

Hariri, D., Meyer, M., Le Gouis, J., Bahrman, N., Fouchard, M., Forget, C. and Andre, A. 2000. Characterization of BaYMV and BaMMV pathotypes in France. Eur. J. Plant Pathol. 106:365-372.

Huth, W. and Adams, M. J. 1990. Barley yellow mosaic virus (BaYMV) and BaYMV-M: two different viruses. Intervirology 31:38-42.

Kanyuka, K., Ward, E. and Adams, M. 2003. Polymyxa graminis and the cereal viruses it transmits: a research challenge. Mol. Plant. Pathol. 4:393-406.

Kashiwazaki, S., Ogawa, K., Usugi, T., Omura, T. and Tsuchizaki, T. 1989. Characterization of several strains of barley yellow mosaic virus. Ann. Phytopathol. Soc. Jpn. 55:16-25.

Kawada, N. 1991. Resistant cultivars and genetic ancestry of the resistance genes to barley yellow mosaic virus in barley (Hordeum vulgare L.). Bull. Kyushu Natl. Agri. Exp. Stn. 27:65-79.

Konishi, T., Ordon, F. and Furusho, M. 2002. Reactions of barley accessions carrying different rym genes to BaYMV and BaMMV in Japan and Germany. Barley Genet. Newslett. 32:46-48.

Lee, K. J., Kashiwazaki, S., Hibi, T. and So, I. Y. 1996. Properties and capsid protein gene sequence of a Korean isolate of barley mild mosaic virus. Ann. Phytopathol. Soc. Jpn. 62:397-401.

Lee, K. J., So, I. Y. and Kashiwazaki, S. 1998. Isolation and identification of barley yellow mosaic virus in Korea. Korean $J$. Plant Pathol. 14:62-67.

Lee, S. H. 1981. Studies on virus diseases occurring in various crops in Korea. Res. Rept. RDA 23:62-74.

Nomura, K., Kashiwazaki, S., Hibino, H., Inoue, T., Nakata, E., Tsuzaki, Y. and Okuyama, S. 1996. Biological and serological properties of strains of barley mild mosaic virus. J. Phytopathol. 144:103-107.

Okada, Y., Kanatani, R., Arai, S. and Ito, K. 2004. Interaction between barley yellow mosaic disease-resistance genes, rym1 and rym5, in the response to BaYMV strains. Breeding Sci. 54:319-325.

Park, J. C., Rho, T. W., Kim, J. G., Kim, H. M., So, I. Y. and Lee, K. J. 2007. Strain distinction and their distribution of barley yellow mosaic virus based on RAPD analysis in Korea. Korean J. Plant Res. 20:511-517.

Park, J. C., Seo, J. H., Kim, H. M., Lee, K. J., Park, S. L. and Suh, D. Y. 2003. Effect of climatic factors on disease incidence of barley yellow mosaic virus (BaYMV). Korean J. Crop Sci. 48:156-159.

Schenk, P., Sohn, A., Adams, M. J., Antoniw, J. F., Hamacher, J. and Steinbiß, H. H. 1995. Movement of bymoviruses and 
functions of RNA2-encoded proteins of barley yellow mosaic virus. Agronomie 15:387-391.

So, I. Y., Cheong, S. S., Lee, K. J. and Oh, Y. H. 1990. Vector of barley yellow mosaic virus and physio-ecological consideration on its vector. Res. Rept. RDA 33:203-213.

So, I. Y., Cheong, S. S., Lee, K. J. and Oh, Y. H. 1991. Vector of barley yellow mosaic virus and physio-ecological consideration on its vector II. Res. Rept. RDA 34:75-83.

So, I. Y., Lee, K. J., Chon, K. H. and Seo, J. H. 1997. Distribution and screening for barley cultivars resistance to barley yellow mosaic virus and barley mild mosaic virus in Southern Korea. Korean J. Plant Pathol. 13:118-124.

Suh, S. J. 1995. Studies on the classification of barley yellow mosaic virus strains and breeding proposal for resistant barley varieties. Ph. D. thesis. Seoul National University, Seoul, Korea. Toyama, A. and Kusaba, T. 1970. Transmission of soil-borne barley yellow mosaic virus. 2. Polymyxa graminis Led. as vector. Ann. Phytopathol. Soc. Jpn. 36:223-229. 